\title{
Adsorption of Phosphate and Nitrate Using Modified Spent Coffee Ground and Its Application as an Alternative Nutrient Source for Plant Growth
}

\author{
Aisyah Humayro, Hiroyuki Harada*, Kanako Naito \\ Faculty of Environmental Science, Prefectural University of Hiroshima, Hiroshima, Japan \\ Email: *ho-harada@pu-hiroshima.ac.jp
}

How to cite this paper: Humayro, A., Harada, H. and Naito, K. (2021) Adsorption of Phosphate and Nitrate Using Modified Spent Coffee Ground and Its Application as an Alternative Nutrient Source for Plant Growth. Journal of Agricultural Chemistry and Environment, 10, 80-90. https://doi.org/10.4236/jacen.2021.101006

Received: November 25, 2020

Accepted: January 25, 2021

Published: January 28, 2021

Copyright $\odot 2021$ by author(s) and Scientific Research Publishing Inc. This work is licensed under the Creative Commons Attribution International License (CC BY 4.0).

http://creativecommons.org/licenses/by/4.0/

\begin{abstract}
Phosphate $\left(\mathrm{PO}_{4}^{3-}\right)$ and Nitrate $\left(\mathrm{NO}_{3}^{-}\right)$are two main nutrients that cause water eutrophication. In the other hand, the presence of $\mathrm{PO}_{4}^{3-}$ and $\mathrm{NO}_{3}^{-}$is needed for plant growth. The aims of this study are to recycle Spent Coffee Ground (SCG) modified with calcium hydroxide for adsorption $\mathrm{PO}_{4}^{3-}$ and $\mathrm{NO}_{3}^{-}$. The optimum adsorption capacity for $\mathrm{PO}_{4}^{3-}$ and $\mathrm{NO}_{3}^{-}$is $36.74 \mathrm{mg} / \mathrm{L}$ and $20.21 \mathrm{mg} / \mathrm{L}$, respectively. The Freundlich isotherm model was suitable for $\mathrm{PO}_{4}^{3-}$ and $\mathrm{NO}_{3}^{-}$adsorption. The kinetic model for adsorption was linear using Pseudo-second order. The application of modified SCG after enrichment with $\mathrm{PO}_{4}^{3-}$ and $\mathrm{NO}_{3}^{-}$for plant growth (Raphanus sativus) showed optimum growth at a dose of $0.3 \%$ with value of germination index was $203 \%$.
\end{abstract}

\section{Keywords}

Spent Coffee Ground, Adsorption, Calsium Hydroxide, Phosphate and Nitrate, Plant Growth

\section{Introduction}

Water pollution containing high concentration of nutrients such as phosphorus and nitrogen is a serious concern in the environment worldwide, because both are implicated in the eutrophication of receiving water [1]. Phosphorus is released into the aquatic environment through the weathering of rocks and by various human activities [2]. Furthermore, the presence of nitrate ion in drinking water is a potential public health hazard. A high concentration of nitrate 
leads to production of nitrosamine, which is related to cancer [3]. On the other hand, phosphorus in the form of phosphate $\left(\mathrm{PO}_{4}^{3-}\right)$ and nitrogen in the form of nitrate $\left(\mathrm{NO}_{3}^{-}\right)$are an important part of the mechanism of plant growth in agricultural sector.

Several physical-chemical and biological methods have been developed to manage the $\mathrm{PO}_{4}^{3-}$ and $\mathrm{NO}_{3}^{-}$in water, such as ion exchange, chemical precipitation, adsorption and bacterial assimilation method. Adsorption is one of the techniques for removal anions from aqueous solution, which is comparatively more useful and low cost using easily available materials in wastewater treatment has been widely investigated [4].

Coffee is one of the most popular drinks worldwide, a significant quantity of by-products as well (6 Mt/year). As a consequence, the coffee industry is responsible for producing large amounts of coffee residues. One of the residues of coffee produced is Spent Coffee Ground (SCG) [5]. SCG is one of the biomass that is suitable to be used as an adsorbent because it has porous characteristic on its surface. Therefore, SCG is often used as an adsorbent for removal of heavy metal or dyes [6] [7]. Based on the early research, the adsorption of $\mathrm{PO}_{4}^{3-}$ and $\mathrm{NO}_{3}^{-}$using original SCG showed a low adsorption capacity. In this study, we improved the adsorption capacity of SCG treated using calsium hydroxide (hereafter referred to the modified SCG). The addition of calsium hydroxide to carbonization of wood biomass has been shown to adsorb more phosphorus [8]. The evaluation of modified SCG based on initial concentration, effect of $\mathrm{pH}$, adsorbent dosage, isotherm and kinetic model. The final objective of this study is to make SCG as an alternative source of nutrients that contribute to plant growth.

\section{Materials and Experimental Methods}

\subsection{Materials}

The samples of SCG in this study were collected from coffee machine at convenience store in Shobara City, Hiroshima, Japan. First, SCG washed using distilled water and dried in the oven for $1-2$ days at $60^{\circ} \mathrm{C}$. After, it was sifted using test sieve by Tokyo Screen Co., Ltd. with sieving size $425 \mu \mathrm{m}$. Then, SCG immersed in $0.04 \mathrm{M}$ calcium hydroxide solution with ratio of $2 \mathrm{~g}$ of SCG in $160 \mathrm{~mL}$ of calcium hydroxide solution during 24 hours and dried in the oven at $60^{\circ} \mathrm{C}$. The modified SCG washed using distilled water subsequently until $\mathrm{pH}$ become 7.5. All chemicals were either reagent on analytical grade and purchased from Kanto Chemical Co. Inc. and Wako pure chemical corporation.

\subsection{Experiment}

\subsubsection{Adsorption Study}

Evaluation of adsorption characteristics $\mathrm{PO}_{4}^{3-}$ and $\mathrm{NO}_{3}^{-}$in this study was conduct using batch experiments. Stock solution of $\mathrm{PO}_{4}^{3-}$ and $\mathrm{NO}_{3}^{-}$(having concentration of $2000 \mathrm{mg} / \mathrm{L}$ ) were prepared by dissolving $1 \mathrm{~mol} / \mathrm{L}$ nitric acid and 
$0.5 \mathrm{~mol} / \mathrm{L}$ phosphoric acid in distilled water. Some various concentrations (10 $500 \mathrm{mg} / \mathrm{L}$ ) were prepared from which working solution. About $0.2 \mathrm{~g}$ of adsorbent was added to $16 \mathrm{~mL}$ of $\mathrm{PO}_{4}^{3-}$ and $\mathrm{NO}_{3}^{-}$solution. The mixture was subsequently placed in temperature controllable magnetic stirrer for the adsorption process begin. The effect of initial $\mathrm{pH}$ was adjusted from $\mathrm{pH}$ range $1-9$ by hydrochloric acid and potassium hydroxide solution. The $\mathrm{PO}_{4}^{3-}$ and $\mathrm{NO}_{3}^{-}$were determined by standard method (Japan Industrial Standard method JIS KO 102). Adsorption capacity $(q)$ was determined using the following equations:

$$
q=\left(C_{o}-C_{e}\right) V / m
$$

where $q(\mathrm{mg} / \mathrm{g})$ represents the adsorption capacity, $C_{e}$ and $C_{o}(\mathrm{mg} / \mathrm{L})$ stand for equilibrium and initial concentrations, respectively, $V(\mathrm{~L})$ is volume of the solution and $m(\mathrm{~g})$ is the mass of adsorbent.

The effect of adsorbent dosage needed for pot treatment experiment, the aims to determine the best composition of modified SCG in adsorbing $\mathrm{PO}_{4}^{3-}$ and $\mathrm{NO}_{3}^{-}$. Various amount of adsorbent $(0.1,0.2$, and $0.6 \mathrm{~g})$ conducted to $16 \mathrm{~mL} \mathrm{PO}_{4}^{3-}$ and $\mathrm{NO}_{3}^{-}$solution.

\subsubsection{Desorption Study}

Desorption experiments of $\mathrm{PO}_{4}^{3-}$ and $\mathrm{NO}_{3}^{-}$were conducted after the completion of the adsorption experiments. After the supernatant was separated with the adsorbent, the adsorbent immersed in $0.1-0.5 \mathrm{M}$ sodium hydroxide for 24 hours. The desorption amount and the rate of desorption were calculated as follow:

$$
\begin{aligned}
q_{\text {des }} & =\left(C_{1} \times V\right) / m \\
D(\%) & =\left(q_{\text {des }} / q\right) 100 \%
\end{aligned}
$$

where $D$ is the rate of desorption, $q_{\text {des }}(\mathrm{mg} / \mathrm{g})$ is the desorption amount of $\mathrm{PO}_{4}^{3-}$ and $\mathrm{NO}_{3}^{-}, V(\mathrm{~L})$ is the volume of desorption solution, $C_{1}(\mathrm{mg} / \mathrm{L})$ represents the $\mathrm{PO}_{4}^{3-}$ and $\mathrm{NO}_{3}^{-}$concentration of desorption supernatant and $m(\mathrm{~g})$ is the mass of adsorbent.

\subsubsection{Application for Plant Growth}

From the best treatment of adsorbent dosage, $0.1 \%, 0.2 \%$, and $0.3 \%$ of the fertilizer from modified SCG enrichment with $\mathrm{PO}_{4}^{3-}$ and $\mathrm{NO}_{3}^{-}$mixed with $150 \mathrm{~g}$ of soil in polybag (diameter $8 \mathrm{~cm}$ ). The plant seeds used were Raphanus sativus. Observation of plant height and leaf width was carried out for 10 days.

The acute toxicity of the examined fertilizer was determined based on a plant's germination test. It was made with the fertilizer for modified SCG after adsorption process $(0.1 \%, 0.2 \%$, and $0.3 \%)$ mixed distilled water in ration $1: 10$ and put in a homogenizer for about 1 hour. Then, take the supernatant and put $5 \mathrm{~mL}$ in Petri dishes with 5 seed Raphanus sativus, which were then incubated in the dark at room temperature $\left(25^{\circ} \mathrm{C} \pm 0.5^{\circ} \mathrm{C}\right)$ for 72 hours. The germination index was calculated from equation GI $=G_{e} / G_{k} \times 100$, where $G_{e}$ and $G_{k}$ are the numbers of germinated seeds in the experimental and control series [9]. 


\section{Result and Discussion}

\subsection{Characteristics of the Modified SCG}

Figure 1 shows SEM images of original and modified SCG. SEM was used to observe the morphology of the adsorbent. The porosity of the modified SCG was relatively more formed than the original SCG. The addition of calcium hydroxide gives advantage to SCG for adsorb more $\mathrm{PO}_{4}^{3-}$ and $\mathrm{NO}_{3}^{-}$.

FTIR was used to analyze the functional groups on the adsorbent before and after modified. The spectra are shown in Figure 2, both of original and modified SCG have peak between 3600 and $3200 \mathrm{~cm}^{-1}$ is related to the hydroxyl groups of $\mathrm{O}-\mathrm{H}$ stretching vibration. The hydroxyl groups causes an increase in the
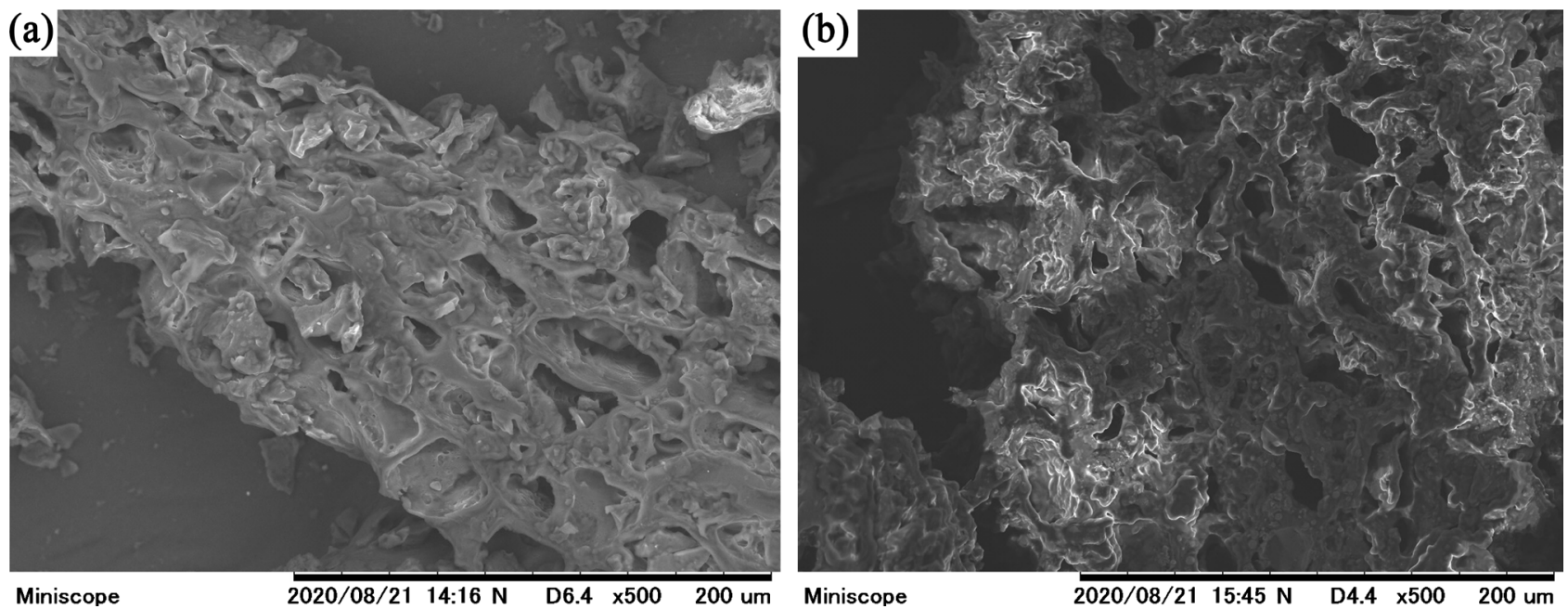

Figure 1. Scanning Electron Microscopy (SEM) images of (a) original and (b) modified Spent Coffee Ground.

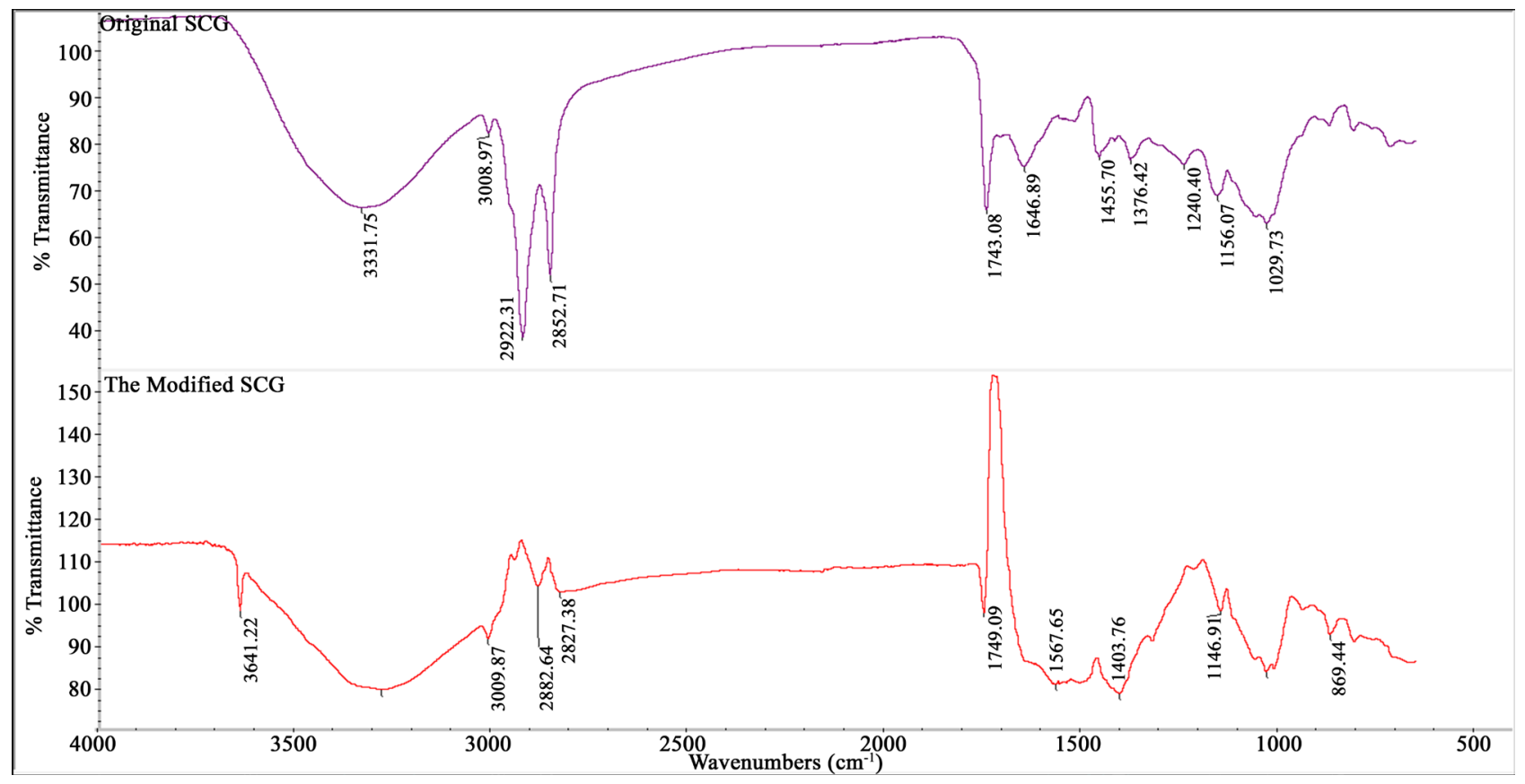

Figure 2. FTIR analysis of original and modified SCG. 
electrostatic adsorption of anions, such as nitrate [10]. The two sharp bands at 2923 and $2852 \mathrm{~cm}^{-1}$ are attributed to C-H stretching vibration. The original SCG has peak between 1700 and $1600 \mathrm{~cm}^{-1}$ is highly associated with chlorogenic acids and caffeine [11]. However, in modified SCG the peak has shifted become 1567 $\mathrm{cm}^{-1}$ due to carboxylate groups [12].

\subsection{Adsorption Phosphate ad Nitrate}

Based on Figure 3 and Figure 4, the figures show that the adsorption capacity of the modified SCG increases than original SCG. The adsorption capacity for $\mathrm{PO}_{4}^{3-}$ is $36.74 \mathrm{mg} / \mathrm{g}$ and for $\mathrm{NO}_{3}^{-}$is $20.21 \mathrm{mg} / \mathrm{g}$, respectively. The $\mathrm{pH}$ of the solution is an important variable in the adsorption process because it affects the surface charge of the adsorbent and also the chemical speciation of the adsorbate [13]. The effect of $\mathrm{pH}$ is showed in Figure 5, in the case of $\mathrm{PO}_{4}^{3-}$ the optimum adsorption occurs at $\mathrm{pH} 3$ and $\mathrm{pH} 1-3$ for $\mathrm{NO}_{3}^{-}$. The modified SCG surface would be positively charged when the solution $\mathrm{pH}$ was lower, which enhanced

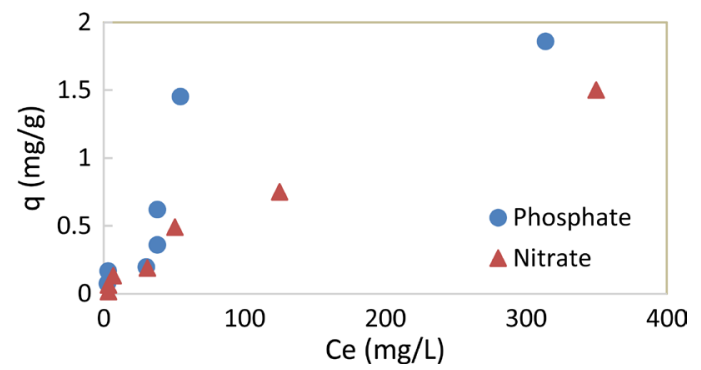

Figure 3. Adsorption of $\mathrm{PO}_{4}^{3-}$ and $\mathrm{NO}_{3}^{-}$by the original SCG $\left(C_{o} 10-500 \mathrm{mg} / \mathrm{L}\right.$, initial $\mathrm{pH}$ solution 3 - 4, ratio liquid/solid $0.1 \mathrm{~L} / 10 \mathrm{~g}, 30^{\circ} \mathrm{C}$ ).

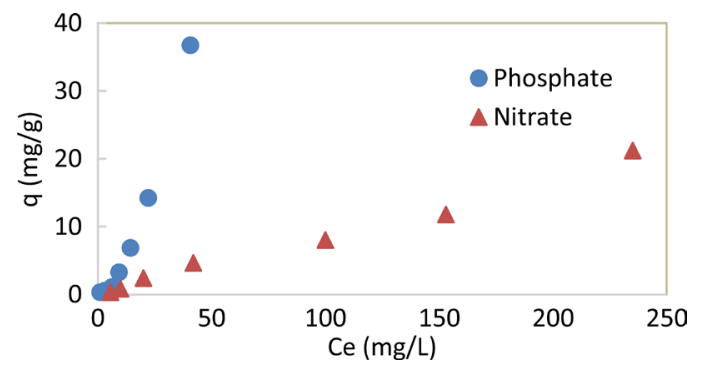

Figure 4. Adsorption of $\mathrm{PO}_{4}^{3-}$ and $\mathrm{NO}_{3}^{-}$by (a) the modified SCG $\left(C_{o} 10-500 \mathrm{mg} / \mathrm{L}\right.$, initial $\mathrm{pH}$ solution $3-4$, ratio liquid/solid $0.016 \mathrm{~L} / 0.2 \mathrm{~g}, 30^{\circ} \mathrm{C}$ ).

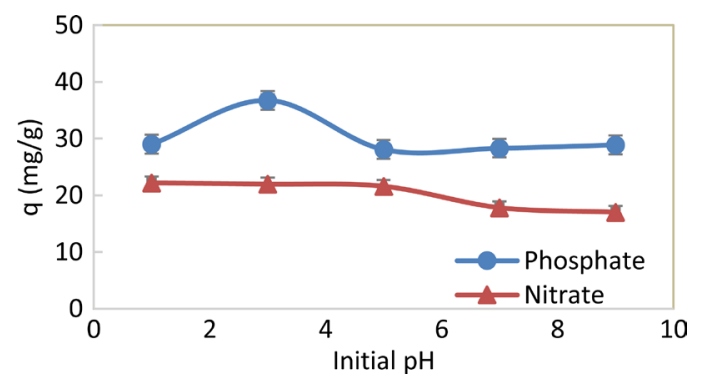

Figure 5. The effect of initial $\mathrm{pH}$ for adsorption $\mathrm{PO}_{4}^{3-}$ and (b) $\mathrm{NO}_{3}^{-}$. 
the adsorption possibility for the negatively charged $\mathrm{PO}_{4}^{3-}$ and $\mathrm{NO}_{3}^{-}$.

Figure 6 shows that the increasing mass of adsorbent doesn't increase the adsorption capacity of $\mathrm{PO}_{4}^{3-}$ and $\mathrm{NO}_{3}^{-}$. Furthermore, the addition of calcium hydroxide has an important role in the adsorption process of $\mathrm{PO}_{4}^{3-}$ and $\mathrm{NO}_{3}^{-}$ The less amount of adsorbent, the more active sites are formed.

\subsection{Adsorption Isotherm Model}

Adsorption isotherm model provide information about the capacity of the adsorbent and the solute-sorbent interaction. In the present work, the Langmuir and Freundlich isotherms were used to analyze the experimental equilibrium data. Table 1 shows the data of (a) Langmuir and (b) Freundlich isotherm models. Figure 7 shows the best fit of adsorption $\mathrm{PO}_{4}^{3-}$ and $\mathrm{NO}_{3}^{-}$.

The Langmuir model is indicating that there is monolayer coverage of adsorbate on a homogeneous adsorbent surface. The Langmuir isotherm equation is [14]:

$$
C_{e} / q_{e}=1 / q_{m} K_{L}+C_{e} / q_{m}
$$

where $q_{m}(\mathrm{mg} / \mathrm{g})$ is the maximum of the adsorption capacity in monolayer condition, $q_{e}(\mathrm{mg} / \mathrm{g})$ is equilibrium capacity, $K_{L}(\mathrm{~L} / \mathrm{mg})$ and $C_{e}(\mathrm{mg} / \mathrm{L})$ is equilibrium concentration. The applicable of isotherm equation is compared on the basis of

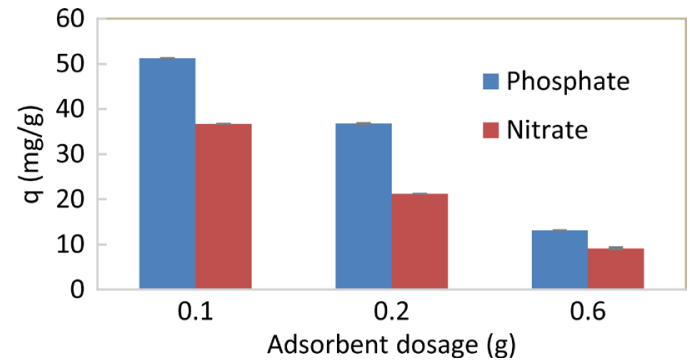

Figure 6. The effect of adsorbent dosage with adsorption capacity.

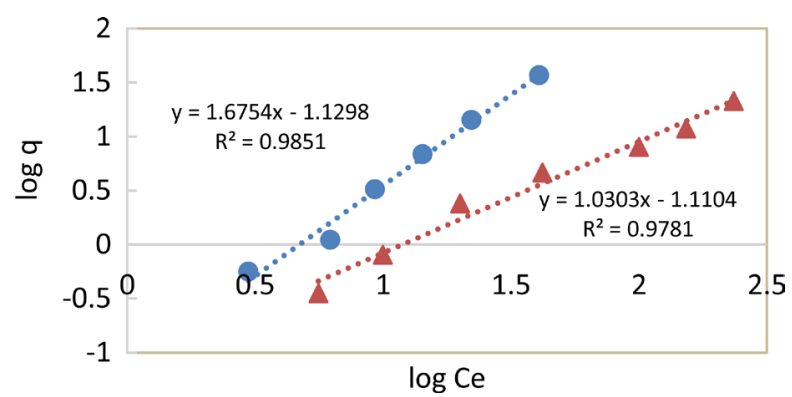

Figure 7. Freundlich isotherm model of $\mathrm{PO}_{4}^{3-}$ and $\mathrm{NO}_{3}^{-}$.

Table 1. Isotherm models of $\mathrm{PO}_{4}^{3-}$ and $\mathrm{NO}_{3}^{-}$adsorption.

\begin{tabular}{cccccccccccccccc}
\hline & \multicolumn{4}{c}{ Phosphate } & \multicolumn{1}{c}{ Nitrate } \\
\hline \multicolumn{3}{c}{ Freundlich } & \multicolumn{3}{c}{ Langmuir } & \multicolumn{3}{c}{ Freundlich } & \multicolumn{3}{c}{ Langmuir } \\
\hline$K_{f}$ & $\boldsymbol{n}$ & $\boldsymbol{R}^{2}$ & $\boldsymbol{K}_{L}$ & $\boldsymbol{q}_{\boldsymbol{m}}$ & $\boldsymbol{R}^{2}$ & $\boldsymbol{K}_{\boldsymbol{f}}$ & $\boldsymbol{n}$ & $\boldsymbol{R}^{2}$ & $\boldsymbol{K}_{L}$ & $\boldsymbol{q}_{\boldsymbol{m}}$ & $\boldsymbol{R}^{2}$ \\
\hline 0.07 & 0.59 & 0.98 & 0.023 & 8.82 & 0.64 & 0.07 & 1 & 0.97 & 0.0001 & 909 & 0.0014 \\
\hline
\end{tabular}


correlation coefficients $\left(R^{2}\right)$. However, $R^{2}$ of Langmuir isotherm model was lower than that of the Freundlich isotherm.

The Freundlich isotherm model is based in assumption that the heterogeneity of the adsorbent material and multi-layer coverage of the adsorbate. The Freundlich isotherm equation is:

$$
\log q=\log K_{L}+1 / n \log C_{e}
$$

where $K_{f}(\mathrm{~L} / \mathrm{mg})$ is the Freundlich isotherm, $n$ is the adsorption intensity, $C_{e}$ ( $\mathrm{mg} / \mathrm{L}$ ) is equilibrium concentration, and $q_{e}(\mathrm{mg} / \mathrm{g}$ ) is the equilibrium capacity.

The best fit of adsorption $\mathrm{PO}_{4}^{3-}$ and $\mathrm{NO}_{3}^{-}$were obtained by the Freundlich with $R^{2}$ values was 0.98 for $\mathrm{PO}_{4}^{3-}$ and 0.97 for $\mathrm{NO}_{3}^{-}$. The data was indicating that adsorption of $\mathrm{PO}_{4}^{3-}$ and $\mathrm{NO}_{3}^{-}$onto the adsorption are not monolayer adsorption. The addition of calcium hydroxide played important role in adsorption $\mathrm{PO}_{4}^{3-}$ and $\mathrm{NO}_{3}^{-}$, which is indicating not only physical adsorption but also chemical adsorption.

\subsection{Adsorption Kinetic Model}

Figure 8 shows the equilibrium time for $\mathrm{PO}_{4}^{3-}$ adsorption is 240 minutes and the optimum time for $\mathrm{NO}_{3}^{-}$is 90 minutes. The kinetic model is used to determine the speed of the adsorption process and the stages that control the adsorption process. The kinetic data obtained is in the form of adsorption capacity, which can be obtained through modeling using pseudo-first order and pseudo-second order models. To find out the appropriate kinetic model for the adsorption system of $\mathrm{PO}_{4}^{3-}$ and $\mathrm{NO}_{3}^{-}$, it is necessary to describe the relationship between the concentration of $\mathrm{PO}_{4}^{3-}$ and $\mathrm{NO}_{3}^{-}$adsorbed and equilibrium with time. The kinetics of $\mathrm{PO}_{4}^{3-}$ and $\mathrm{NO}_{3}^{-}$adsorption by modified SCG was investigated by pseudo-first order and pseudo-second order models [15], were determined using the following equations:

$$
\begin{aligned}
& \ln \left(q_{e}-q_{t}\right)=\ln q_{t}-k_{1} t \\
& t / q_{t}=\left(1 / k_{2} q_{e}^{2}\right)+t / q_{e}
\end{aligned}
$$

where $k_{1}$ is the pseudo-first order adsorption rate constant, $k_{2}$ is the pseudosecond order rate constant, $q_{e}(\mathrm{mg} / \mathrm{g})$ is the adsorption capacity at equilibrium, and $q_{t}(\mathrm{mg} / \mathrm{g})$ is the adsorption capacity at $t$ (minute). Figure 9 shows that both adsorption data is more linear using the pseudo-second order adsorption

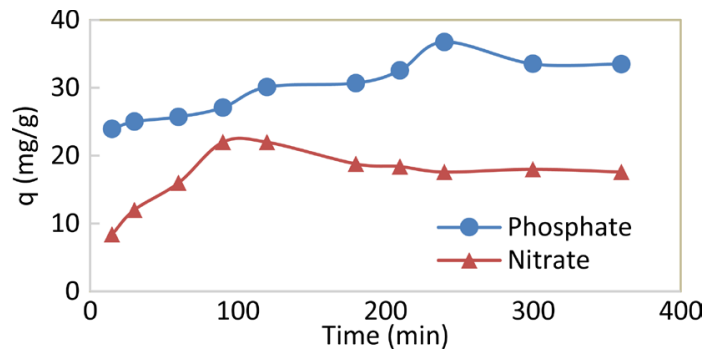

Figure 8. Equilibrium time of $\mathrm{PO}_{4}^{3-}$ and $\mathrm{NO}_{3}^{-}$adsorption. 
kinetic model, evidenced by the $R^{2}$ value of 0.9791 for $\mathrm{PO}_{4}^{3-}$ and 0.9347 for $\mathrm{NO}_{3}^{-}$.

\subsection{Desorption Studies}

Adsorption by chemical bonding or ion exchange or combination of both, then desorption can be effected by stronger desorbent like acid or alkali solution. If the adsorption is by physical bonding then the loosely bound metal ion can be easily desorbed with distilled water in most of the cases. The result of $\mathrm{PO}_{4}^{3-}$ desorption rate using sodium hydroxide solution showed results reaching $24.35 \%$, while the optimum value for desorption of $\mathrm{NO}_{3}^{-}$reached $39.39 \%$. These results indicate that the adsorption on the adsorbent modified SCG is not completely reversible and bonding between it and adsorbed $\mathrm{PO}_{4}^{3-}$ and $\mathrm{NO}_{3}^{-}$is likely to be be strong. Thus, it is relatively difficult to desorb $\mathrm{PO}_{4}^{3-}$ and $\mathrm{NO}_{3}^{-}$ from the modified SCG [16].

\subsection{Application for Plant Growth}

The application of modified SCG after enrichment with $\mathrm{PO}_{4}^{3-}$ and $\mathrm{NO}_{3}^{-}$for plant growth (Raphanus sativus) can be seen in Figure 10 and Figure 11. The dose of $0.3 \%$ was a significant growth in the plant height and leaf width. However, seeds can grow on the third day. It is estimated because of the chemical bonds between $\mathrm{PO}_{4}^{3-}$ and $\mathrm{NO}_{3}^{-}$in the active site of modified SCG are quite strong. Therefore, nutrients need time to release into the soil. It is linear with a desorption

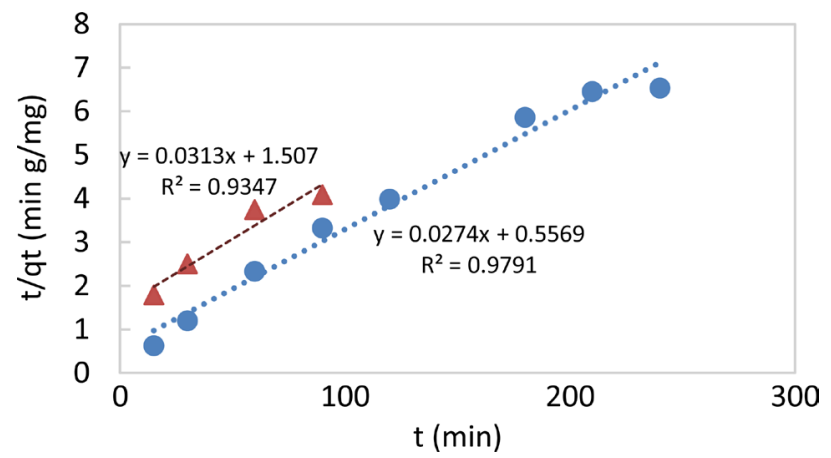

Figure 9. Pseudo-second order of (a) $\mathrm{PO}_{4}^{3-}$ and (b) $\mathrm{NO}_{3}^{-}$.

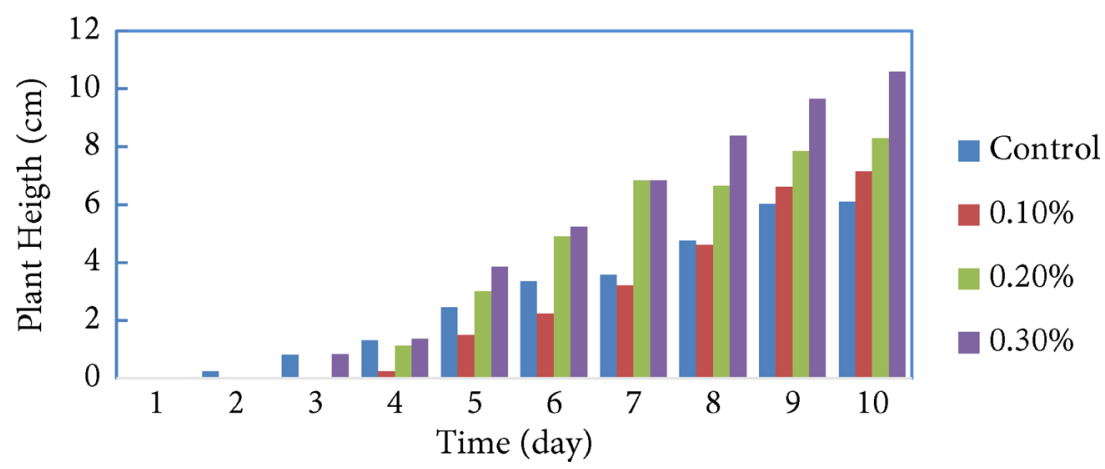

Figure 10. The effect of modified SCG enrichment on stem height of Raphanus sativus. 


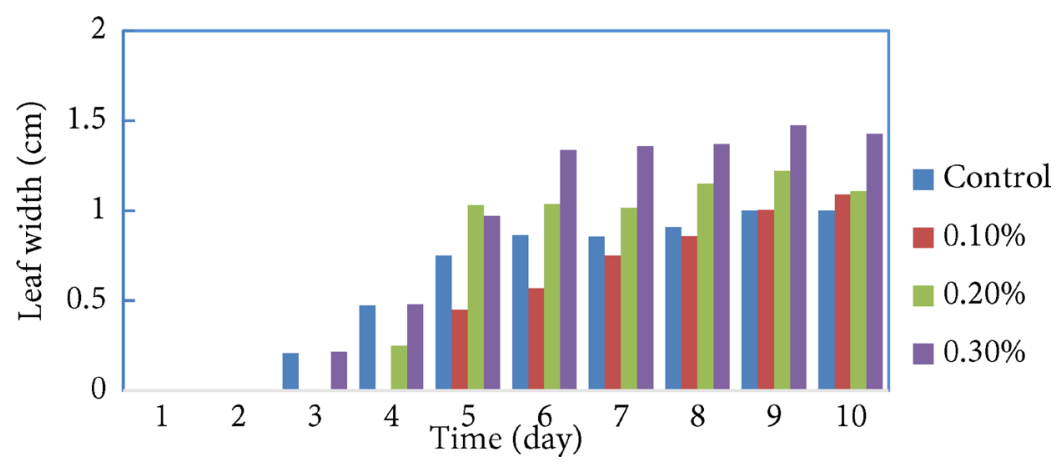

Figure 11. The effect of modified SCG enrichment on leaf width of Raphanus sativus.

Table 2. Germination Index (GI) of Raphanus sativus.

\begin{tabular}{ccc}
\hline Concentration & Germination Index (\%) & Root Length (cm) \\
\hline $0.10 \%$ & 177 & 3.4 \\
$0.20 \%$ & 200 & 3.8 \\
$0.30 \%$ & 203 & 3.9 \\
\hline
\end{tabular}

rate of only $26 \%-30 \%$.

The original SCG is characterized by a strong phytotoxic impact, such as caffeine content [17]. Caffeine $(1.8 \mathrm{mg} / \mathrm{g})$ present in SCG may serve as a chemical defense mechanism in some plants [5]. FTIR data on the original SCG indicated that there was a peak associated with caffeine content. However, the addition of sodium hydroxide has the effect of lowering caffeine levels in SCG. The effect of toxicity can also be seen from the germination rate test. The result of germination rates in Table 2 shows that even though the small dose of fertilizer can contribution to plant growth significantly.

\section{Conclusion}

The optimum adsorption capacity at equilibrium $(q)$ of $\mathrm{PO}_{4}^{3-}$ was $36.74 \mathrm{mg} / \mathrm{g}$ when $\mathrm{pH}$ and contact time of $\mathrm{PO}_{4}^{3-}$ solution were 3 and 240 minutes. The optimum adsorption capacity at equilibrium adsorption capacity at equilibrium of $\mathrm{NO}_{3}^{-}$was $20.21 \mathrm{mg} / \mathrm{g}$ when $\mathrm{pH}$ and contact time were $1-3$ and 90 minutes, respectively. The best fit of the experimental data $\mathrm{PO}_{4}^{3-}$ and $\mathrm{NO}_{3}^{-}$were obtained by the Freundlich isotherm and pseudo-second order. The desorption rate of the modified SCG ranged from $24 \%$ - 39\%. It can be concluded that the modified SCG can be used as an adsorbent to remove $\mathrm{PO}_{4}^{3-}$ and $\mathrm{NO}_{3}^{-}$in wastewater. The fertilizer from modified SCG after enrichment with $\mathrm{PO}_{4}^{3-}$ and $\mathrm{NO}_{3}^{-}$can contribute to plant growth even though in small dose, so it can use as an alternative source of nutrients that contribute to plant growth.

\section{Acknowledgements}

This research was supported by Prefectural University of Hiroshima. Also, I would thank to Kumahira scholarship for financial funding this study. 


\section{Conflicts of Interest}

The authors declare no conflicts of interest regarding the publication of this paper.

\section{References}

[1] Jorgensen, S.E., and Williams, W.D. (2001) Water Quality: The Impact of Eutrophication. International Environmental Technology Centre, Osaka.

[2] Chitrakar, R., Tezuka, S., Sonoda, A., Sakane, K., Ooi, K. and Hirotsu, T. (2006) Phosphate Adsorption on Synthetic Geothite and Akagenite. Journal of Colloid and Interface Science, 298, 602-608. https://doi.org/10.1016/j.jcis.2005.12.054

[3] Kioussis, D.R., Wheaton, F.W. and Kofinas, P. (2000) Reactive Nitrogen and Phosphorus Removal Aquaculture Wastewater Effluents Using Polymer Hydrogels. $A q$ uaculture Engineering, 23, 315-332. https://doi.org/10.1016/S0144-8609(00)00058-3

[4] Yin, Q., Zhang, B., Wang, R. and Zhao, Z. (2017) Biochar as an Adsorbent for Inorganic Nitrogen and Phosphorus Removal from Water: A Review. Environmental Science and Pollution Research, 24, 26297-26309. https://doi.org/10.1007/s11356-017-0338-y

[5] Vega, R.C., Pina, G.L., Castenada, H.A.V. and Oomah, B.D. (2015) Spent Coffee Grounds a Review on Current Research and Future Prospects. Trends in Food Science and Technology, 45, 24-36. https://doi.org/10.1016/j.tifs.2015.04.012

[6] Anastopoulos, I., Karamesouti, M., Mitropoulos, A. and Kyzas, G. (2017) A Review for Coffee Adsorbents. Journal of Molecular Liquids, 229, 555-565. https://doi.org/10.1016/j.molliq.2016.12.096

[7] Fiol, N., Escudero, C. and Villaescusa, I. (2008) Re-Use of Exhausted Ground Coffee Waste for Cr(VI) Sorption. Separation Science and Technology, 43, 582-596. https://doi.org/10.1080/01496390701812418

[8] Watanabe, R., Takase, T. and Asada, T. (2012) Carbonization of Wood Biomass Loaded with Calcium and Its Use in Phosphorus Removal from an Aqueous Solution. Journal Carbon, 52, 621-622. https://doi.org/10.1016/j.carbon.2012.09.042

[9] Molnarova, M., Smelkova, M. and Fargasova, A. (2014) Assessment of The Suitability of Phytotoxkit Plastic Vertical Containers Compared with Petri Dishes for Standard Seedling Growth Test. Bulletin of Environment Contamination and Toxicology, 92, 497-501. https://doi.org/10.1007/s00128-013-1186-1

[10] Bhatnagar, A. and Sillanpaa, M. (2011) A Review of Emerging Adsorbent for Nitrate Removal from Water. Chemical Engineering Journal, 168, 493-504.

https://doi.org/10.1016/j.cej.2011.01.103

[11] Craig, A.P., Franca, A.S., and Oliviera, L.S. (2012) Evaluation of the Potential of FTIR and Chemomectrics for Separation between Defective and Non-Devective Coffees. Food Chemistry, 132, 1368-1374. https://doi.org/10.1016/j.foodchem.2011.11.121

[12] Mitra, S., Siahkali, A.G., Kingshott, P., Hvilsted, S. and Almdal, K. (2006) An Investigation on Changes in Chemical Properties of Pure Ethylene-Propylene-Diene Rubber in Aqueous Acidic Environments. Material Chemistry and Physics, 98, 248-255. https://doi.org/10.1016/j.matchemphys.2005.09.028

[13] Rattanapan, S., Srikaram, J. and Kongsune, P. (2017) Adsorption of Methyl Orange on Coffee Ground Activated Carbon. Energy Procedia, 138, 949-954.

https://doi.org/10.1016/j.egypro.2017.10.064 
[14] Langmuir, I. (1918) Adsorption of Gases on Glass, Mica and Platinum. Journal of the American Chemical Society, 40, 1361-1403. https://doi.org/10.1021/ja02242a004

[15] Wang, J. and Guo, X. (2020) Adsorption Kinetic Models: Physical Meaning, Applications, and Solving Methods. Journal of Hazardous Material, 360, Article ID: 122156. https://doi.org/10.1016/j.jhazmat.2020.122156

[16] Taleb, M.F.A., Mahmoud, G.A., Elsigeny, S.M., and Hegazy, E.A. (2008) Adsorption and Desorption of Phosphate and Nitrate Ions Using Quaternary (Polypropylene-g- $N, \mathrm{~N}$-dimethylamino Ethylmethacrylate) Graft Copolymer. Journal of Hazardous Materials, 159, 372-379. https://doi.org/10.1016/j.jhazmat.2008.02.028

[17] Ciesielczuk, T., Dulewska, C.R., Poluszynska, J., Milek, D., Szewczyk, A. and Slawinska, I. (2018) Acute Toxicity of Experimental Fertilizer Made of Spent Coffee Grounds. Waste and Biomass Valorization, 9, 2157-2164.

https://doi.org/10.1007/s12649-017-9980-3 